\title{
Attendance Technology on Campus Research and Application
}

\author{
Li Jiang \\ Ningbo DaHongYingUniversity \\ Ningbo, china
}

\author{
Yan $\mathrm{Li}$ \\ Ningbo DaHongYingUniversity \\ Ningbo, china
}

\begin{abstract}
The phenomenon of cutting a class is increasingly more serious in university, leading to a lot of universities begin to strengthen the daily management for students. The students of class attendance is the most common method. This paper introduces some management can be used in the technology in classroom attendance, through the introduction of the technology, the managers of university can have pointed choice to strengthen students' attendance management.
\end{abstract}

Keywords-attendance technology; campus; research; application

\section{INTRODUCTION}

In the college students' study, there is no doubt that classroom education is the most important segment, through the teacher's words and by example, College students can quickly grasp all kinds of knowledge, improving personal qualities. But, there is a general phenomenon in the university campus---Cut class. "Choose fled, elective courses " will be the class standards for many students, and a class only have a few people scene happens very often; Some class ,although ,there are many people in the class, the phenomenon such as late for class, leaving early ,skipping classes and class occurred frequently. In this case, some university started to supervise students with strict management or urge teachers to strengthen the classroom management and the roll call attendance. But in university teaching process, a student need to face more than teachers' teaching, but each teacher exists between the information asymmetry, the teacher and the students' management department also exists between information asymmetry phenomenon. So individual teacher and students can't understand a manager of the students all attendance information. The attendance management system application solved the problem, has been developed for the application of students ways of checking on work attendance.

\section{BASED ON C/S OR B/S CHECKING ATTENDANCE SYSTEM}

There must have the students' class attendance management system in universities of educational administration management system, the premise of the system application is the teachers in the classroom of the roll, submitting the data in system after school. System can realize the function of statistics, but the permission shortcomings is not so good, and student worker management can't effective use of this system. Some colleges and universities also developed this type of system independently to improve, and makes education student worker linkage, multi-channel joint management of student attendance, but this way after class attendance to teachers in time to submit the information roll call during class, increases the teacher of work after class.

\section{CONTACT ATTENDANCE TECHNOLOGY}

\section{A. The application of the cassette attendance}

One of the technology is attendance machine of paper, this way of the attendance wide applications, a lot of small companies are using it. The advantage is easy to use, and the cost is low, but the disadvantage is more trouble statistical data, data vulnerable, vulnerability is more also. This way is not really suitable for college students to the management, the reason is data quantity is too big, CARDS and powder ink will often appear shortages, and wasting paper, not environmental protection, punch machine failure rates is high.

A credit card is in the form of attendance machine. At present, this attendance way is used widely, many units make worker card to this unit the exclusive, during rush hour in the form of credit card in attendance. The way used in universities are also common. Almost all of the university are 
extended to the campus card id, dining on campus shopping books lending etc. Some universities campus card integrated function in attendance, in some teaching building dormitory, set some attendance machine. Using the campus CARDS way for attendance. And then use the background management function, for the information of attendance statistic summary analysis, etc.

\section{B. Fingerprint attendance technology}

Because each person's fingerprints are has uniqueness, and lifelong unchanged. So we can extract the fingerprint to analyze the characteristics, find out the difference between each fingerprints, so as to distinguish between provide fingerprints. Fingerprint identification technology is the fingerprint characteristics that based on the analysis and is a technology that researches to identify individual. This technology is the premise of the establishment of a complete fingerprint database. Today, fingerprint identification technology has quite mature, and to be widely used in many areas. In practical application, we can go through fingerprints read equipment, use the tool of analysis to analysis fingerprint characteristics, and extract characteristic value, and then fingerprint characteristic value of the Treasury fingerprint match. Fingerprint attendance solved the cheating in attendance fraud phenomenon to a certain degree, but with the appearance of the fingerprint membrane, fingerprint fraud is also can be realized.

\section{The iris recognition of attendance technology.}

Iris identification is a technology that with the eyes of biological recognition to the person produces less interference. It uses quite common camera components, and don't need users make contact with the machine. In addition, it has the ability to achieve higher template matching performance. In all biological recognition technology, iris identification is the most convenient and accurate application.

\section{NON-CONTACT ATTENDANCE TECHNOLOGY}

\section{A. Face Recognition Technology.}

Face recognition technology is widely used in the regional characteristics analysis algorithm, face recognition as processing technology and biological principles of statistics in one body, using computer image processing technology to extract portrait feature points from video, and then using the principle of biological statistics analysis established the mathematical model, that is, face feature template. Using the completed face feature template with those tested people face like feature analysis, according to the results of the analysis are given to a similar values, through this value can determine whether for the same person. We can use this technology to carry out student attendance, attendance accurate, can avoid the phenomenon of cheating in attendance, but the cost of attendance is too big.

\section{B. Based on a variety of style of RFID checking attendance} system is a typical non-contact attendance technology.

RFID (Radio Frequency Identification) RFID is a non-contact automatic Identification technology, it through Rf signal automatic target recognition to access relevant data. Identifying work without human intervention, and it can work in all kinds of bad environmental conditions. RFID technology can identify the moving objects and identify multiple tags, the operation is fast and convenient. RFID technology basic working principle is the label into the magnetic field, and then receiving a RF signal from reader, with inductive current energy for sending the information which is stored in charge of the product. (Passive Tag ,Passive tags or passive tags), or sending a frequency tags with initiative of the signal (Active Tag, Active tags or active tags ). Reading is the decoding and read information, send to the central information system on the data processing. A complete set of RFID systems, is made by the Reader (Reader) and electronic TAG (TAG) or the so-called response device (Transponder) and application software system of three parts. The working principle of Reader of the radio waves launch specific frequency energy to the Transponder. To drive Transponder circuit will internal data sent out, at this time and sequence receive Reader reading data, give application made corresponding processing.

Based on the mobile phone of RFID checking attendance system. In the mobile phone SIM card to a launch of honshui attendance information function, through the receiver is responsible for the information processing.

Based on the second generation id card RFID attendance system. Use of the second generation id card reading card equipment combined with attendance function, we can effective to the school attendance for students timekeeping and summary. At present the attendance has also been way social promotion, but in the campus there was no be used. Another attendance way also involves id information security problems, so many units are more cautious.

Based on the campus card RFID attendance system. It is also a very feasible campus attendance way that we can 
integrate the campus card into the RFID ,and then use the campus card for wireless attendance.

\section{SUMMARIZE}

Because the number of students in colleges and universities are big, so the application contact attendance technology, is easy to form queuing phenomenon. So it will lead to class late for the initiative, and make students produce psychological resistance. And based on the application of RFID non-contact attendance technology, we can avoid above consequences, and also can make the attendance efficiency is greatly increased. But no matter what attendance technology we use, teacher's classroom attendance management is an important link in the process of teaching.

\section{REFERENCES}

[1] HAN Pu, XU Chun-yu, WANG Hua-bin: The Design and Implementation of an Attendance System Based on RFID-SIM Phone.J.Vol.7, No. 34, December 2011.

[2] ChengYujuan, Yao Jiandong, Wang Yihuai: RFID ENTRANCE GUARD AND ATTENDANCE MANAGEMENT SYSTEM BASED ON SECOND-GENERATION ID CARD.J. Computer Applications and Software . Vol 28 No. 3 ,2011

[3] ZHANG Yu-Jie, MENG Xiang-Wu .Attendance Management System Based on LBS. J.Computer System Application.2011.20(10). 